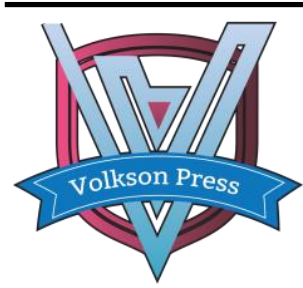

Contents List available at VOLKSON PRESS

Engineering \& Technology Innovations (ETI)

\title{
INFLUENCE OF RECONSTRUCTION SLAG ON THE PROPERTIES OF CEMENFBASED MATERIALS
}

\author{
Lei Zhang 1,2,3, Yanan Zhang1, Fangfang Wu'1, Ruihua Liang ${ }^{1}$
}

(1. College of Materials Science and Engineering, Tianjin Chengjian University, Tianjin 300384, China; 2.Key Laboratory of Soft Soil Engineering Character and Engineering Environment of Tianjin, Tianjin 300384, China; 3. Engineering Research Centre of Construction Waste and Coal Waste Recycle Technology of Tianjin, Tianjin 300384, China)

Author:LeiZhang(1979-),male,Ph.D.,associateprofessor,researchdirectionforbuildingmaterialsandecological materials,

E-mail: zhanglei@tcu.edu.cn

This is an open access article distributed under the Creative Commons Attribution License, which permits unrestricted use, distribution, and reproduction in any medium, provided the original work is properly cited

\section{ARTICLE DETAILS}

\section{Article History:}

Received 02 october 2017 Accepted 06 october 2017 Available online 11 october 2017

Keywords:

cement-based materials; MSWI fly ash; reconstruction slag; properties

\section{ABSTRACT}

Melting the mixture of municipal solid waste incineration (MSWI) fly ash and slag with mass ratio $3: 7$ at $1400^{\circ} \mathrm{C}$ for $60 \mathrm{~min}$, and then obtained reconstruction slag by air cooling. The effect of reconstruction slag with the dosages of $10 \%, 30 \%, 50 \%$ on the properties of cement-based materials were studied, and the activity of reconstruction slag and raw slag was also contrasted. Furthermore, the influence mechanism of reconstruction slag on the properties of cement-based materials was analyzed by scanning electron microscopy (SEM), X-ray diffraction (XRD). It turned out that the compressive strength showed a trend of decrease after the first increase of the specimen with the increased of reconstruction slag, the compressive strength reach to $45.0 \mathrm{MPa}$ at curing $28 \mathrm{~d}$ with the dosage of $30 \%$. The activity of reconstruction slag was higher than the raw slag. Microscopic analysis showed that reconstruction slag contains a certain amount of gehlenite crystals, under alkaline environment, second hydration occur to reconstruction slag, and it generate large numbers of hydration products to make a high strength.

\section{INTRODUCTION}

The production of municipal solid waste incineration (MSWI)is growing at a rate of $8 \% \sim 10 \%$ per year recently [1]. With the increasing generation of municipal solid waste, as well as the disadvantages of traditional waste landfill, composting and other disposal methods, incineration is becoming a scientific and effective method of waste disposal at the advantage of large capacity reduction, harmless and resource utilization. However, incineration will generate MSWI fly ash which account for $10 \% \sim 15 \%$ of the total incineration waste, and MSWI fly ash is classified as hazardous waste because of its relatively high amount of dioxin and toxic heavy metals (lead, cadmium, chromium, etc.), which require solidification treatment before disposal to avoid polluting soil and groundwater ${ }^{[2-4]}$.

At present, many researchers have focused on resource utilization of MSWI fly ash and solidification/stabilization of heavy metals in MSWI fly ash. The resource utilization are mainly concentrated on the use of MSWI fly ash in cement industry, as building materials, as the landfill cover material, thepreparation of microcrystalline glass,or in agriculture,and so on ${ }^{5]}$. While solidification/stabilization of heavy metals mainly concentrated on solidification by cement, high temperature sintering /melting solidification, chemical agent stabilization, composite solidification, and so on. These researchs have made remarkable achievements ${ }^{[6-8]}$ in the disposal of MSWI fly ash.

The solidification/stabilization methods what are said above mainly focuse on the single disposal of MSWI fly ash, there were less research on codisposal of MSWI fly ash with other solid waste. Blast furnace slag is a sort of industrial solid waste, it has been widely used as mineral admixtures with its unique composition and structure. Large quantities of heat will be emited in the process of output slag in industrial, this article intends to utilize the waste heat to melt MSWI fly ash with slag,therefore, a kind of reconstruction slag will be obtained. The reconstruction slag can be applied in building materials , thus the utilization of waste slag can be improved, the disposal effect of MSWI fly ash can be enhanced, and the pollution will be reduced to environment. Herein, MSWI fly ash melting reconstruction slag was prepared by the method of air cooling ,firstly. Then, the influence of reconstruction slag at different dosages on the properties of cement-based materials will be researched, and the activity of reconstruction slag with raw slag will be contrasted. Moreover, the influence mechanism of reconstruction slag on the properties of cementbased materials was studied by scanning electron microscope (SEM), and $\mathrm{X}$-ray diffraction (XRD).

\section{Experimental}

\subsection{Raw materials}

(1) MSWI fly ash: provided by taida environmental protection Co., Ltd. Chemical compositions analyzed by X-ray fluorescence spectrometer (XRF) was shown in table 1 . Mineral compositions analyzed by X-Ray diffraction (XRD) was shown in figure 1 (a), analysis results showed that the main mineral compositions were $\mathrm{CaAl}_{2} \mathrm{SiO}_{6}, \mathrm{NaCl}, \mathrm{KCl}, \mathrm{CaCO}_{3}, \mathrm{SiO}_{2}$, $\mathrm{MgCO}_{3}$ and $\mathrm{CaSO}_{4}$.

(2) Slag:provided by building commodity concrete mixing co., Ltd. Chemical compositions and mineral compositions were shown in the following table 1 and figure 1 (b) respectively, XRD analysis show that the main mineral composition was amorphous.

(3)Reconstruction slag: simulation on using the waste heat of industrial product blast furnace slag to melting MSWI fly ash. Specific operation is: Melting the mixture of municipal solid waste incineration (MSWI) fly ash and slag with mass ratio $3: 7$ at $1400^{\circ} \mathrm{C}$ in muffle furnace, open the oven door after $60 \mathrm{~min}$ to take out the molten material, reconstruction slag will be obtained with the method of rapid cooling of fan, then grinding it to a certain fineness. Chemical compositions analyzed by X-ray fluorescence spectrometer (XRF) was shown in table 1. Mineral compositions analyzed by X-Ray diffraction (XRD) was shown in figure 1 (a), the results show that the main mineral compositions were amorphous and gehlenite, etc.

(4) Cement: $\mathrm{P} \bullet 042.5$, provided by hebei jidong cement factory .

(5)Sand: standard sand.

(6)Water: drinking water. 
Tab.1 The chemical composition of experiment material /wt $\%$

\begin{tabular}{|c|c|c|c|c|c|c|c|c|}
\hline \multirow{2}{*}{ No. } & \multicolumn{4}{|c|}{ Compositions /\% } & \multicolumn{2}{|c|}{$\begin{array}{l}\text { flexural } \\
\text { strength } \\
/ \mathrm{MPa}\end{array}$} & \multicolumn{2}{|c|}{$\begin{array}{l}\text { compressive } \\
\text { strength / } \mathrm{MPa}\end{array}$} \\
\hline & $\begin{array}{l}\text { Ceme } \\
\text { nt }\end{array}$ & $\begin{array}{l}\text { MSW } \\
\text { I fly } \\
\text { ash }\end{array}$ & slag & $\begin{array}{l}\text { reconst } \\
\text { ruction } \\
\text { slag }\end{array}$ & $3 \mathrm{~d}$ & $28 \mathrm{~d}$ & $3 \mathrm{~d}$ & $28 \mathrm{~d}$ \\
\hline A0 & 100 & 0 & 0 & 0 & 5.3 & 8.7 & 20.9 & 50.1 \\
\hline K & 70 & 0 & 30 & 0 & 2.3 & 7.2 & 11.6 & 40.0 \\
\hline B1 & 90 & 0 & 0 & 10 & 3.0 & 7.5 & 14.8 & 44.7 \\
\hline B3 & 70 & 0 & 0 & 30 & 3.2 & 7.7 & 16.9 & 45.0 \\
\hline B4 & 50 & 0 & 0 & 50 & 2.9 & 7.1 & 12.5 & 40.6 \\
\hline
\end{tabular}

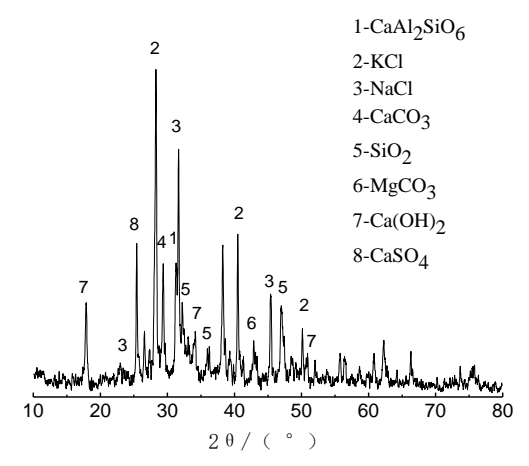

(a) MSWI fly ash

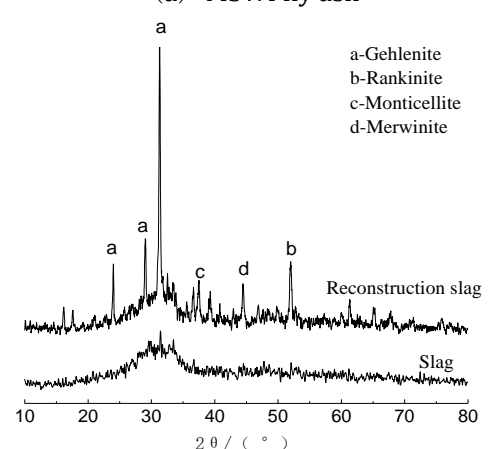

(b) slag

Fig.1 The XRD analysis diagram of MSWI fly ash、slag、 reconstruction slag

\subsection{Experimental methods}

2.2.1 Influence of reconstruction slag on properties of cement mortar To study the influence of reconstruction slag on properties of cementbased materials, $40 \times 40 \times 160(\mathrm{~mm})$ cement mortar specimens with water/ binding material(W/B)ratio of 0.5 were prepared at different mixture proportions according to table 2.The specimens were kept in constant temperature and humidity curing box at $20 \pm 1^{\circ} \mathrm{C}$, above $90 \%$ relative humidity,then the flexural, compressive strength of specimens at differene curing time( $3 \mathrm{~d}$ and $28 \mathrm{~d}$ ) will be tested.

\subsubsection{Influence mechanism of reconstruction slag on the properties} of cement-based materials

The hydration productions in central region of cement-based materials at different curing time(3d,28d)were cut out. UltimaIV XRD was used to test mineral composition of the cement hydration productions.JSM-7800F SEM was used to research microstructure images of the cement hydration productions.

\section{Results and discussion}

3.1 Influence of reconstruction slag on properties of cement mortar
The mechanical properties of cement mortar were given in table 3 and figure 2. It can be seen that the strength of cement mortar with different dosages of reconstruction slag strength were lower than the pure cement mortar . The compressive strength showed a trend of decrease after the first increase of the specimens mixed with reconstruction slag $(10,30,50 \%)$,it had the mix flexural strength of $7.7 \mathrm{MPa}$ and the compressive strength of $45.0 \mathrm{MPa}$ at curing $28 \mathrm{~d}$ with the dosage of $30 \%$. The cement mortar with reconstruction slag had higher strength than mortar with raw slag at the same dosage of $30 \%$. It showed that reconstruction slag with air cooling had higher activity than raw slag, the cement mortar strength were growing rapidly in the later stages of the hydration. The reasons for the above phenomenons were mainly as follows : firstly, XRD analysis showed that reconstruction slag contained a large number of amorphous and a certain amount of gehlenite crystals, but the main mineral of raw slag was amorphous substances, some other researchs also showed that reconstruction slag with some crystals had better activity ${ }^{[9]}$, that was because a small amount of crystallization filled in the gaps of cement paste structure to make it more densely and enhance the strength of mortar; furthermore, in alkaline environment, the unstable state of amorphous structure in reconstruction slag collapsed and released some substances like $\mathrm{AlO}_{4}{ }^{5+} 、 \mathrm{Al}^{3+} 、 \mathrm{SiO}_{4}{ }^{4-}$ in the process of hydration, these substances made secondary hydrate reaction with $\mathrm{Ca}(\mathrm{OH}))_{2}$, and generate more hydrated calcium silicate (C-S-H),thus made the cement mortar had high strength ${ }^{[10]}$.

Tab. 2 The mechanical properties of cement mortar

\begin{tabular}{|c|c|c|c|c|c|c|c|c|}
\hline \multirow{2}{*}{ No. } & \multicolumn{4}{|c|}{ Compositions /\% } & \multicolumn{2}{|c|}{$\begin{array}{l}\text { flexural } \\
\text { strength } \\
/ \mathrm{MPa}\end{array}$} & \multicolumn{2}{|c|}{$\begin{array}{l}\text { compressive } \\
\text { strength / MPa }\end{array}$} \\
\hline & $\begin{array}{l}\text { Ceme } \\
\text { nt }\end{array}$ & $\begin{array}{l}\text { MSW } \\
\text { I fly } \\
\text { ash }\end{array}$ & slag & $\begin{array}{l}\text { reconst } \\
\text { ruction } \\
\text { slag }\end{array}$ & $3 d$ & $28 \mathrm{~d}$ & $3 d$ & $28 \mathrm{~d}$ \\
\hline A0 & 100 & 0 & 0 & 0 & 5.3 & 8.7 & 20.9 & 50.1 \\
\hline K & 70 & 0 & 30 & 0 & 2.3 & 7.2 & 11.6 & 40.0 \\
\hline B1 & 90 & 0 & 0 & 10 & 3.0 & 7.5 & 14.8 & 44.7 \\
\hline B3 & 70 & 0 & 0 & 30 & 3.2 & 7.7 & 16.9 & 45.0 \\
\hline B4 & 50 & 0 & 0 & 50 & 2.9 & 7.1 & 12.5 & 40.6 \\
\hline
\end{tabular}

\subsection{XRD patterns of hardened cement paste at different curing time \\ 3.3}

The main crystalline compounds identified by XRD in the hydration products at different curing time were shown in Figure 2.As can be seen in figure 2, the principle crystalline hydrates were ettringite and $\mathrm{Ca}(\mathrm{OH})_{2}$, the XRD patterns of different mixture proportions were similar. With the dosages increased of reconstruction slag ,the peaks of ettringite and $\mathrm{Ca}$ $(\mathrm{OH})_{2}$ became weaker at the same curing time, characteristic peaks of Ca $(\mathrm{OH})_{2}$ and $\mathrm{C}_{3} \mathrm{~S}$ at curing $28 \mathrm{~d}$ was weaker than that at curing $3 \mathrm{~d}$,but characteristic peaks of ettringite became stronger. This is mainly due to the volcanic activity of reconstruction slag, the hydration reaction diminished with the dosages increased of reconstruction slag, which lead to the amount of hydration products decreased in the early stage of hydration; in the late stage of hydration, secondary hydration occurred to reconstruction slag in the stimulation of $\mathrm{Ca}(\mathrm{OH})_{2}$ generated by hydration of cement, the active $\mathrm{SiO}_{2}$ and $\mathrm{Al}_{2} \mathrm{O}_{3}$ in reconstruction slag reacted with $\mathrm{Ca}$ $(\mathrm{OH})_{2}$, and generated a large amount of C-S-H and ettringite, which lead to a high strength of cement mortar.

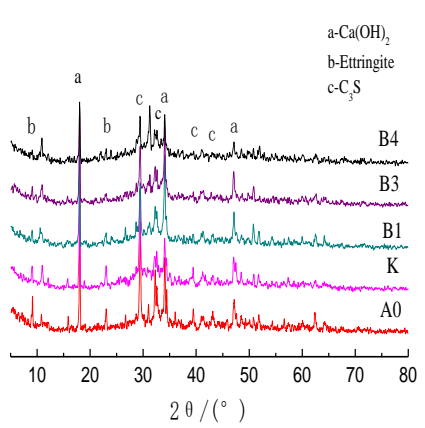

(a) XRD patterns of hardened cement paste at curing 3d 


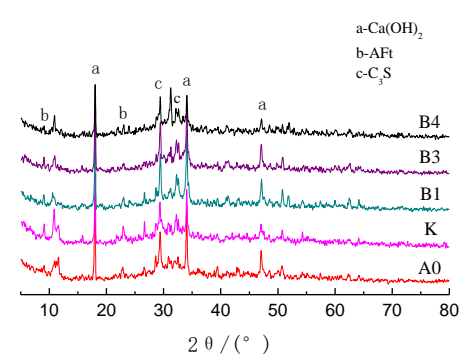

(b) XRD patterns of hardened cement paste at curing 28d

Fig.2 XRD patterns of hardened cement paste at different curing time

\subsection{SEM images of hardened paste at different curing time 3.5}

The SEM images of cement paste with different mixture proportions at curing $28 \mathrm{~d}$ were shown in figure 3.It can be seen that the hydration products contain needle bar ettringite , $\mathrm{C}-\mathrm{S}$ - $\mathrm{H}$ as well as the six-party slab $\mathrm{Ca}(\mathrm{OH})_{2}$, the cement paste at curing $28 \mathrm{~d}$ had more hydration products than that at curing $3 \mathrm{~d}$, and the structure was more densely, so with the higher strength .The surface of cement particles were covered with hydration products like C-S-H, ettringite and so on. When the reconstruction slag dosages were $10 \%$ and $30 \%$, needle bar ettringite overlap each other, and form a dense microstructure. Along with the increased of reconstruction slag, the amount of hydration products reduced, more cracks appears on the hardened body structure, thus weaken the strength of cement mortar (as shown in table 2). The hydration products of cement paste with reconstruction slag were more than that with raw slag at the same dosage of $30 \%$,and it had more dense structure just as shown in figure 3(K and B3),so with the higher activity of reconstruction slag.

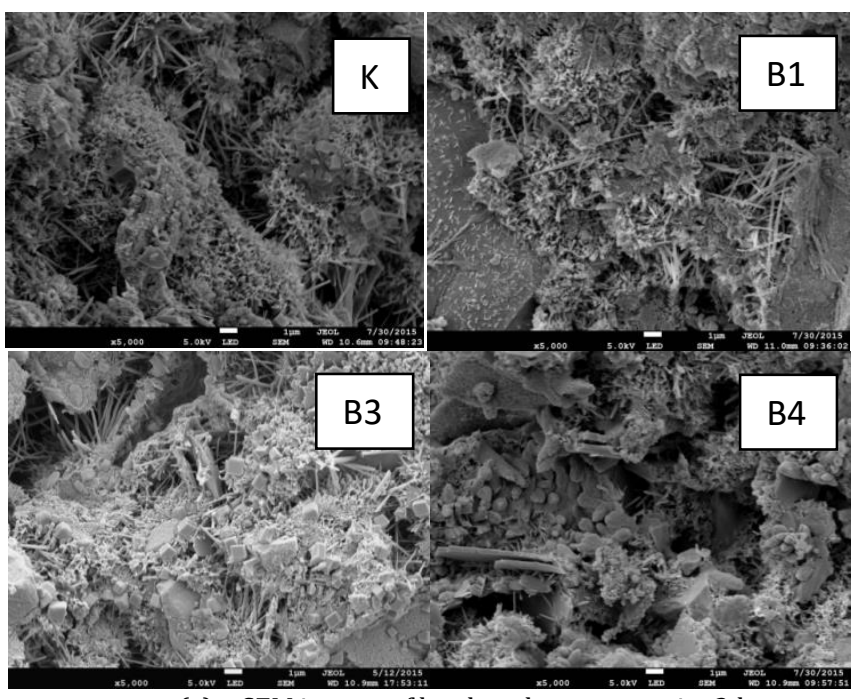

(a) SEM images of hardened paste at curing3d

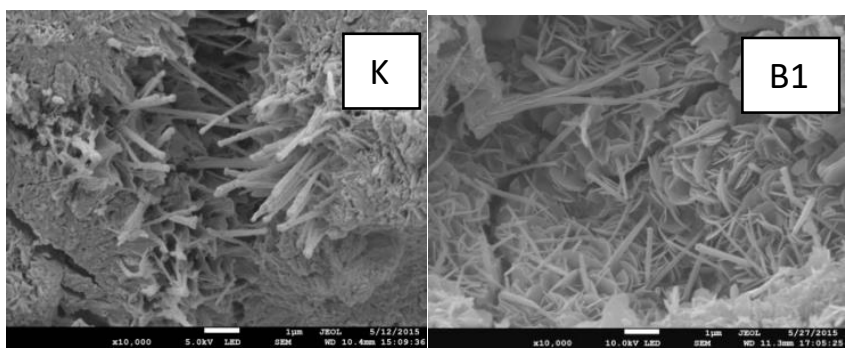

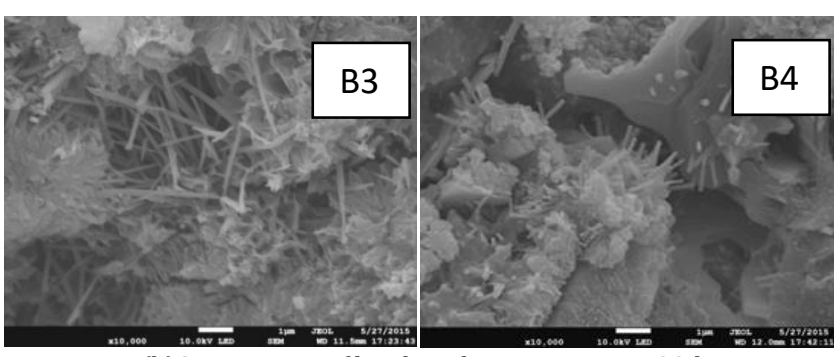

(b)SEM images of hardened paste at curing 28d

Fig.3 SEM images of hardened paste at different curing time

\section{Conclusions}

a)The activity of reconstruction slag obtained by air cooling after melting $60 \mathrm{~min}$ at $1400^{\circ} \mathrm{C}$ was higher than raw slag. The strength of cement mortar with different dosages of reconstruction slag strength were lower than the pure cement mortar. With the dosage increase of reconstruction slag, strength of cement mortar decreased afterthe first increased, and reached to maximum $45.0 \mathrm{Mpa}$ at curing $28 \mathrm{~d}$ with $30 \%$ of the mass of reconstruction slag.

b)Reconstruction slag contains a certainamount of gehlenite crystals,under alkaline environment, second hydration occur toreconstruction slag,and it generate largenumbers of hydration products to make high strength of cement mortar. Furthermore ,the influence of reconstruction slag on properties of concrete will be researched to expand the using scope of reconstruction slag.As a result, the construction slag can be used in building material, turning waste into wealth andachieve the goal of the resource utilization.

\section{Acknowledgements}

We gratefully acknowledge the support of this research by Tianjin Applic ation foundation and Advanced Technology Research Program (Grant No. 14JCZDJC40800)

\section{References}

[1] Kebing Cai, Xiaochun Peng, Renbin Yang. Progress of Disposal and Utilization of Fly Ash from MSW Incineration[J]. Environmental Science and Management, 2012 ,37 (4):30-34.

[2] Huisheng Shi. The treatment technology of municipalsolid waste and resources-recovery in cement production[J].Cement,2007,10:1-4.

[3] Qinhong Zhang. Current Status of Municipal SolidWaste (MSW) Incineration in China[J]. Boiler Manufacturing,2006,(3):41-42.

[4] Zhiquan Yang, Shaoqi Zhou. Investigation Development on the Control of Heavy Meatal from MSW Incineration Flue Gas Ash [J]. Environmental Sanitation Engineering, 2005,13(4):36-40.

[5] Xinming Li, Shige Wang. Advancement of Study onUtilizing Fly Ash Resource from MSW Inceneration []]. Thermal Power Generation, 2010,39 (5):1-5.

[6] Junli Zhang, Jianguo Liu ect.Comparison of the fixation of heavy metals in raw material, clinker and mortar using a BCR sequential extraction procedure and NEN7341 test[J]. Cement and Concrete Research, 2008, 38 :675-680.

[7] Zhongtao Luo, Yuling Xiao, Jiujun Yang.Progress on the solidification of toxic heavy metals in municipal solid waste incinerationflyash [J]. Environmental Pollution\&Control, 2012,34(8):58-62.

[8] Polettini A, Pomi.R, Fortuna E. Chemical activation in view of MSWI bottom ash recycling in cement-based systems[J]. Journal of Hazardous Materials, 2009, 162(2): 1292-1299.

[9] Hui Wang.The forming process and performance study of blast furnace slag[D]. Beijing University of Technology : Bei Jing,2013,6. [10]Zhongzheng Yang. Inorganic Bond Material[M]. Zhengzhou University Publisher: Zheng Zhou,2008. 